\title{
Outra narrativa no ensino da Reforma Sanitária Brasileira: o debate crítico de uma escolha política
}

\author{
An alternative narrative in the teaching of the Brazilian Sanitary \\ Reform: the critical debate of a political choice
}

Leonardo Carnut', Áquilas Mendes ${ }^{\mathbf{2}, \mathbf{3}}$, Maria Cristina da Costa Marques $\mathbf{2}$

DOI: $10.1590 / 0103-110420195810$

\begin{abstract}
RESUMO A Reforma Sanitária Brasileira constitui capítulo fundamental para a compreensão da história da saúde coletiva. Em que pese a relevância do tema, existe uma tendência em enfatizar o ensino desse conteúdo na trajetória institucional das políticas em detrimento da 'escolha política' feita. Nessa perspectiva, este artigo teve como objetivo construir outra narrativa para o ensino da Reforma Sanitária, por meio do resgate dos argumentos de três autores filiados à matriz marxista: Sergio Arouca, Jaime de Oliveira e Jairnilson Paim. São trabalhados, para fins didáticos, textos específicos desses autores em períodos sócio-históricos distintos, tidos como fontes essenciais para compreender as escolhas políticas realizadas pelo movimento da Reforma. Sobre os materiais analisados, foram considerados como corpora de análise os excertos dos textos que abordavam as categorias fundamentais para uma análise marxista. Tomou-se como unidade de texto as proposições que dialogavam entre as categorias e a escolha política da Reforma Sanitária apresentada pelos autores. Conclui-se que a construção dessa outra narrativa para o ensino da Reforma Sanitária Brasileira pode contribuir para a ampliação de um pensamento crítico ao futuro da saúde pública no País, em contexto de crescentes restrições democráticas.
\end{abstract}

PALAVRAS-CHAVE Política. Sistema Único de Saúde. Sistemas de saúde. Ensino. História.

1 Universidade Federal de São Paulo (Unifesp) - São Paulo (SP), Brasil.

leonardo.carnut@gmail.com

2 Universidade de São Paulo (USP) - São Paulo (SP), Brasil.

3 Pontifícia Universidade Católica de São Paulo (PUC-SP), Programa de Estudos Pós-Graduados em Economia Política - São Paulo (SP), Brasil.
ABSTRACT The Brazilian Sanitary Reform is a fundamental chapter for understanding the history of collective health. In spite of the relevance of the theme, there is a tendency to focus the teaching of this content on the institutional trajectory of policies to the detriment of the 'political choice' that were made. In this perspective, this article aims to construct an alternative narrative for the teaching of the Sanitary Reform, through the rescue of the arguments of three authors affiliated to the Marxist thought, namely, Sergio Arouca, Jaime de Oliveira, and Jairnilson Paim. Specific texts of these authors are used for didactic purposes in distinct socio-historical periods, considered as essential sources for understanding the political choices made by the Reform movement. The excerpts of the texts that deal with the categories that are fundamental for a Marxist analysis were considered as corpus of analysis. Proposals that conversed between the categories and the political choice of the Sanitary Reform presented by the authors were taken as the unity of the text. It is concluded that the building up of this other narrative for the teaching of the Brazilian Sanitary Reform can contribute to the expansion of a critical thought about the future of public health in the country, in the context of the increasing democratic restrictions.

KEYWORDS Politics. Unified Health System. Health systems. Teaching. History. 


\section{Introdução}

O estudo da Reforma Sanitária Brasileira (RSB), no âmbito das ciências da saúde, é um capítulo fundamental do que se considera como o conteúdo essencial da área de 'história da saúde pública/coletiva'1. Em que pese a relevância do tema, existe uma tendência em enfatizar a trajetória normativa e institucional das políticas de saúde ${ }^{2}$ em detrimento do ensino baseado na 'escolha política' realizada pelo movimento sanitário na década de 1970-1980. É reconhecida na literatura da saúde coletiva que esta escolha política se referiu à ocupação de posições estratégicas no aparelho do Estado ${ }^{3,4}$.

Durante o processo de formação dos profissionais de saúde ${ }^{5}$, pouco tem sido investido no estudo da história da saúde coletiva/pública no sentido de resgatar alguns autores clássicos ${ }^{6}$ da Reforma Sanitária, com vistas a rever suas contribuições ao debate da escolha política encetada por esse movimento. Das poucas vezes que esse resgate é feito, uma parcela de professores e de estudantes se limita aos aspectos institucionais, ou seja, a priorização do ensino/estudo das normas e regras que conformam o Sistema Único de Saúde (SUS) em políticas públicas de saúde ${ }^{7,8}$.

Tradicionalmente, há uma visão romântica, e até saudosista, do Movimento da Reforma Sanitária como fonte de inspiração socialista que gradualmente se perdeu ao longo da implantação do SUS. Entretanto, por esse conteúdo ser pouco trabalhado nas graduações de saúde, especialmente nas de saúde coletiva ${ }^{9}$, adentra-se superficialmente no intenso cenário de disputa que fez com que a tese socialista, logo de partida, fosse abandonada em nome de uma ideologia política social-democrata1,10,11 em que se privilegiou a ocupação institucional.

A importância de se apoiar em uma nova narrativa para a escolha política do Movimento da Reforma Sanitária, sob a crítica da filiação social-democrata, encontra ancoradouro em Breilh $^{12}$. Este considera que é fundamental, sobretudo em momentos de mudanças políticas, apoiar as reflexões sobre a saúde coletiva na história crítica. Breilh ${ }^{12}$ aponta que isso proporcionaria uma melhor compreensão das raízes emancipadoras da prática em saúde e, também, do arcabouço do pensamento crítico sanitário latino-americano.

Mesmo a RSB sendo um acontecimento histórico com diversos autores-atores ${ }^{\mathbf{1 3}}$, considera-se que, para fins didático-pedagógicos, a eleição de representantes da perspectiva crítica deve ser feita, à medida que pode contribuir para o ensino do entendimento da escolha política tomada pela Reforma. Nesse sentido, para efeito deste artigo, prioriza-se o estudo de textos específicos de Sergio Arouca, Jaime de Oliveira e Jairnilson Paim, autores-atores considerados como alguns dos expoentes que representam as contradições vivenciadas na corrente de pensamento marxista nesta arena política.

A crítica e outras narrativas são elementos que dialogam com o que atualmente se pensa sobre o ensino de história. Além disso, possibilitam a compreensão sobre a capacidade que esta tem de apostar na transformação e projeção de um novo futuro por meio da recuperação crítica do passado. Tal questão alça o professor ao patamar de saber lidar com o tempo passado e tê-lo como uma matéria-prima, cujas contradições devem ser exploradas e explicadas para contribuir para a construção de uma sociedade melhor que a passada e daquela em que se está vivendo ${ }^{14}$.

Assim, este artigo tem como objetivo construir outra narrativa para o ensino da RSB por meio do resgate dos argumentos de três autores filiados à matriz marxista (Arouca, Oliveira e Paim). São trabalhados, para fins didáticos, textos específicos desses autores em períodos sócio-históricos distintos, tidos como fontes essenciais para ajudar a compreender as escolhas políticas realizadas pelo movimento da Reforma Sanitária enquanto ideia-processo'.

Este artigo está estruturado em duas partes e considerações finais. A primeira parte trata do percurso metodológico produzido ao longo do contato dos pesquisadores-professores 
deste artigo com os textos utilizados como fontes históricas e como material didático. A segunda parte apresenta um breve descritivo do 'lugar de fala' dos autores-atores trabalhados e evidencia seus argumentos para explicitar as contradições internas do debate marxista sobre a escolha política realizada no decurso da Reforma.

\section{Percurso metodológico}

Foi realizada uma análise de conteúdo ${ }^{15}$ de três textos dos autores clássicos da saúde coletiva que apresentam discussões importantes para a reflexão crítica sobre o desenvolvimento da RSB, em três períodos distintos: a) o primeiro texto, relacionado com o período pré-reforma (1975), do professor Sergio Arouca" ${ }^{11}$, intitulado: 'Medicina preventiva e sociedade' da sua tese de doutorado intitulada: 'O dilema preventivista: contribuição para compreensão e crítica da medicina preventiva'; b) o segundo artigo, relacionado com o período da reforma (1987), do sanitarista Jaime de Oliveira ${ }^{10}$, publicado na revista 'Saúde em Debate', intitulado: 'Para uma teoria da reforma sanitária: democracia progressiva e políticas sociais', e, por fim c) o terceiro texto, relacionado com o período pós-reforma (2008), do professor Jairnilson da Silva Paim', oriundo de sua tese de doutorado: 'Reforma Sanitária e revolução passiva no Brasil'.

Sobre os materiais analisados (um artigo científico e dois capítulos de livro), foram considerados como corpora de análise os excertos dos textos que abordavam as categorias fundamentais para uma análise marxista. Assim, as categorias 'troca', 'mercadoria', 'valor' e 'Estado' foram aquelas que guiaram a delimitação do corpus no texto do Sérgio Arouca. As categorias 'luta de classes' e 'Estado' foram objeto de delimitação do corpus no texto elaborado por Jaime de Oliveira. Já em Jairnilson Paim, as categorias-guias de extração do corpus foram 'Estado', 'reforma' e 'revolução'.

Após a pré-análise e a devida identificação das categorias (tanto em forma manifesta como latente), considerou-se como unidade textual as proposições ${ }^{15}$ que continham o conteúdo essencial para o debate. Portanto, essas unidades de texto foram identificadas como fundamentais para iniciar a construção de outra narrativa de ensinar a história da Reforma Sanitária, ressaltando as categorias essenciais para a compreensão marxista do debate que se sucedeu ao longo destes três momentos em que os textos foram escritos (1975, 1987 e 2008).

Essas categorias podem ser consideradas 'indicadores' do conteúdo marxista na interpretação sobre o decurso histórico descrito ('ideia-processo') apenas pelas análises-vivências dos autores-atores. Diante disto, foi possível reconstruir outra narrativa que ressaltasse o conteúdo da escolha política tomada pela Reforma.

A perspectiva conceitual de autores 'clássicos' da saúde coletiva adotada neste artigo é aquela descrita por Brandão ${ }^{6}$, segundo o qual, o estudo dessas referências é importante pelas proposições e bases empíricas que apontam para a qualidade de testemunhos do seu tempo, fonte de problemas e de questões teóricas para a investigação científica na atualidade. $\mathrm{O}$ autor ainda considera que esse tipo de estudo permite compreender as linhagens de pensamento no campo e sua persistência.

Assim, é pertinente ratificar que este estudo não se caracteriza com uma 'análise histórica' da pluralidade da Reforma Sanitária nem uma historiografia em 'grande angular'. Considerase que, de forma menos ousada, foi apenas uma identificação textual localizada de três autores-atores em períodos históricos distintos que narram suas percepções sobre a Reforma Sanitária devidamente apoiados em uma perspectiva crítica marxista. Portanto, a fim de assegurar a precisão analítica do que se empreendeu neste trabalho, tratou-se de uma compreensão inicial da análise marxista usada pelos autores-atores a partir do texto, e pelo texto, sem pretensões indutivas aos seus contextos.

Por fim, é essencial ressaltar que a abordagem utilizada neste artigo não trata de considerar a história como 'mestra da vida', inclusive em desarmonia com os métodos 
profissionais de fazer e compreender a disciplina histórica. Assim, este estudo apoia-se na concepção de que a história tem funções, e uma delas é permitir a desnaturalização de estruturas e formas de pensar de diferentes épocas, possibilitando a ressignificação de eventos e contextos, sempre no âmbito de teorias e formas de pensar específicas.

\section{Construindo outra narrativa para o ensino da história da Reforma Sanitária}

\section{Arouca: da 'crítica ao 'cuidado' médico' ao 'primeiro adeus à tese socialista'}

O sanitarista Sergio Arouca foi um dos principais teóricos e líderes do chamado 'movimento sanitário', que mudou a concepção da saúde pública no Brasil. A consagração do movimento veio com a Constituição de 1988, quando a saúde se tornou um direito social de todos os cidadãos, como está escrito na Carta Magna.

Falecido aos 61 anos, em 2 de agosto de 2003, Arouca é reconhecido por sua produção científica e pela liderança conquistada na construção do SUS. Foi presidente da Fundação Oswaldo Cruz (Fiocruz) em 1985, professor concursado da Escola Nacional de Saúde Pública (Ensp/ Fiocruz), além de chefe do Departamento de Planejamento da Escola.

A tese de doutorado de Arouca, intitulada ' $\mathrm{O}$ dilema preventivista: contribuição para a compreensão e crítica da medicina preventiva', forneceu fundamentos teóricos estruturantes para a constituição da base conceitual da saúde coletiva e para a crítica à 'medicina preventiva' (pensamento hegemônico da saúde pública à época).

Em Arouca, a crítica ao pensamento preventivista inicia como a crítica ao 'cuidado médico' e suas condições na sociedade capitalista. Para esse autor, tem-se que:
O cuidado médico representa uma dupla característica, a primeira de ser um processo de trabalho que tem como objetivo a intervenção sobre os valores vitais (biológicos e psicológicos) e a segunda, ao atender necessidades humanas, de ser uma unidade de troca à qual é atribuída, social e historicamente, um valor11(153).

Nesse trecho, Arouca"1 se baseia na teoria de valor desenvolvida por Marx ${ }^{\mathbf{1 6}}$, na tentativa de explicitar a percepção do 'cuidado médico' como um processo de trabalho que gera valor. Sua intenção era contrapor-se ao pensamento clássico ${ }^{17}$ que considera o 'cuidado médico' como um 'serviço'18 que não produz valor'19. Com o objetivo de caracterizar bem o sentido da expropriação do valor no 'trabalho médico', Arouca"1 ${ }^{11}$ complementa que:

As características básicas do cuidado médico definem um espaço, no qual vamos encontrar a contradição fundamental da medicina, ou seja, as margens entre o vital e o social, uma vez que, definindo como seu objeto o vital que é influenciado pelo social, é neste lugar que a medicina encontra os seus limites e as suas possibilidades. Dirigindo-se em forma de cuidados a valores vitais, a sua contradição fundamental reside em ter estes valores como objeto e o uso atribuído social e historicamente a estes valores11(155).

A partir desse momento, Aroucan demonstra sua opção em construir uma argumentação orientada a explicitar a contradição do processo de trabalho médico, que, inevitavelmente conduz ao que ficou conhecido na saúde coletiva como o processo de 'determinação social da saúde e doença'20,21. Nesse sentido, sua tentativa era de demonstrar que todas atividades do processo de trabalho médico, inclusive a 'prevenção' (à época reconhecida como uma atividade basicamente educativa, focada nos sujeitos individualmente baseada na convicção de uma certa 'autonomia/neutralidade política' da saúde) ${ }^{22}$ é capturada pela 
lógica da expropriação do valor característica do processo de trabalho no modo de produção capitalista. Arouca ${ }^{11}$ sintetiza:

Nossa tese é que, em primeiro lugar, o discurso preventivista aparece como uma das primeiras reinterpretações do setor médico às novas determinações da ordem econômica, reinterpretação esta que se faz ainda em termos de uma ideologia liberal. A medicina, durante a primeira metade do século, manteve, em grande parte do mundo capitalista, um caráter predominantemente liberal, mantendo, por assim dizer, na instância ideológica, as mesmas ligações que possibilitaram o nascimento da clínica. Porém, não só o capitalismo desenvolveu-se no sentido do capitalismo monopolista e multinacional, como a própria medicina desenvolveu-se enquanto organização de produção, distribuição e consumo dos cuidados médicos ${ }^{\mathbf{1 1}(165)}$.

Com a identificação da posição dessa premissa fundamental, Arouca ${ }^{11}$ vai descortinar como a produção de um discurso preventivista (que advoga pelo uso de ações médicas de identificação das doenças em suas fases 'subclínicas') ${ }^{\mathbf{2 3}}$ também pode ser objeto da ideologia liberal. Nesse sentido, o processo de mercantilização do ato preventivo não aparece, ainda, como contraponto à lógica capitalista, mas com uma atividade mercadorizada que pode, potencialmente, transformar-se em objeto de produção de capital. Aroucan nos alerta que:

A medicina privada (ou liberal) transformou o cuidado médico em mercadoria, mas não transformou a sua prática em atividade capitalista, já que os lucros, obtidos e divididos entre uma população dispersa de profissionais, não permitiram a transformação do dinheiro em capital, sendo gasto na maior parte das vezes, em um consumo de luxo. Assim, neste setor constituiu-se uma fração de classe de alto consumo, mas de baixa densidade, de realização de capital, e o volume de dinheiro circulante no setor prevê um espaço de ampliação altamente viável para a expansão das atividades capitalistas 11(166-197).

A partir de então, Arouca11 identifica a principal contradição inerente ao discurso preventivista e sua submissão à lógica do capital. Se o 'cuidado médico' tem como valor fundamental a produção da vida, então a lógica capitalista tem na prevenção a intenção de repor a força de trabalho de forma mais acelerada possível. Ao repor apressadamente o trabalhador, o mantém sob as mesmas condições de adoecimento que, por outrora, o levou a adoecer. Ou seja, há uma conveniência do discurso preventivista à lógica de produção capitalista no qual a prevenção se molda à necessidade de geração de uma massa de trabalhadores sempre submissa às condições de exploração. Para Arouca11, é importante compreender que:

Desta maneira, as atitudes preventivistas são incorporadas ao trabalho médico segundo as características das várias formas deste trabaIho e segundo as classes sociais a que ele se dirige, porém o fundamental é que a eficiência destas práticas encontra-se exatamente colocada sobre a contradição fundamental da Medicina, já que o uso atribuído à vida como força de trabalho a ser consumido no processo produtivo é o núcleo gerador fundamental das patologias. A eficiência (ou impacto) das medidas preventivas choca-se, em última instância, contra a base fundamental do modo capitalista de produção11(171-172).

Diante desse diagnóstico, a grande contradição na análise de Arouca"1 sobre o trabalho médico e o discurso preventivista reside na extrapolação de sua perspectiva de luta a partir das considerações que faz do Estado como promotor da 'rearticulação' do setor saúde. Na perspectiva marxiana, como disposto por Marx em 'Crítica ao Programa de Gotha'24, as questões sociais, quando subvencionadas pelo Estado, favorecem basicamente àqueles que detêm o poder da máquina governamental, já que o Estado tem como função precípua a 
sustentação do modo de produção capitalista por meio de suas formas jurídicas.

Assim, o argumento de Arouca"1, ao depositar no Estado a possibilidade de reorganização do setor saúde, em especial ao processo de trabalho médico, pode ser considerado como uma ilusão do ponto de vista da 'fidelidade teórica marxiana', arcabouço que o autor usou para analisar a questão. Contudo, do ponto de vista histórico, é necessário afirmar que as condições objetivas do Brasil no contexto de escrita de sua tese (auge da ditatura militar) sugeriam que a aposta no Estado Democrático era o caminho possível que guiava os horizontes do movimento sanitário. Aroucan ${ }^{11}$ reforça esse papel do Estado argumentando que:

O Estado pode promover uma rearticulação do setor de saúde, mantendo as funções da Medicina diante da sociedade capitalista, através de uma reorganização do trabalho médico, de uma recolocação do seu poder político e de um controle das indústrias ligadas ao setor. Evidentemente, tal procedimento pode levar a uma maior eficácia no desenvolvimento das funções da Medicina diante da sociedade, pela introdução de um sistema racionalizador do trabalho médico. Neste caso, as concepções preventivistas podem se incorporar à prática, abandonando seu berço de origem junto à sociedade civi|11(172).

Nesse caso, Arouca ${ }^{11}$ tornou-se o grande líder da RSB e norteou a confecção do arcabouço jurídico-institucional do SUS. Em que pese a aposta no Estado naquele momento, a luta política pela redemocratização do País e sua organicidade ante as condições de opressão realizadas pelo regime escamotearam a predição que a teoria política marxista apontava, sendo este o primeiro 'adeus' à tese socialista. Apostar no Estado (burguês), sendo ele o sustentáculo do modo de produção capitalista, parece ser a contradição política mais relevante desse período, a qual os estudantes de hoje devem tomar como lição fundamental.

\section{Oliveira: uma crítica contumaz, po- rém, conciliatória}

Ao calor da RSB, diversas teses foram sendo discutidas, ao passo que os reformistas, na tentativa de ler o social de forma mais acurada, tentavam elaborar uma 'teoria da Reforma Sanitária'. A intenção era compreender melhor o momento social vigente e, a partir dessas análises, guiar a luta política pela construção do direito à saúde no Brasil.

Nesse bojo, emergiu o papel significativo de Jaime de Oliveira. Médico, com mestrado em ciência política pelo Instituto Universitário de Pesquisas do Rio de Janeiro, trabalhou no Departamento de Administração e Planejamento da Ensp/Fiocruz e contribuiu para compreender o processo de Reforma Sanitária por meio de duas obras fundamentais: 'Interesses sociais e mecanismos de representação: a política de saúde no Brasil pós-64' de 1983 e '(In)previdência social: 60 anos de história da previdência no Brasil' de 1986.

Oliveira ${ }^{10}$ era de uma corrente contra-hegemônica sobre a tese que guiaria o processo de Reforma Sanitária. Em um lado, havia aqueles autores que apostavam na institucionalidade estatal, tais como Sonia Maria Fleury Teixeira², Sergio Arouca"1 ${ }^{11}$ Roberto Passos Nogueira ${ }^{25}$, e de outro lado, autores que criticavam a institucionalidade estatal, tal qual Oliveira ${ }^{10}$ realizava.

Nas palavras do autor, tem-se que:

[...] no meu entendimento, o conjunto de proposições que gira em torno da ideia de Reforma Sanitária tem seu significado inovador dado pelo fato de que estas proposições apontam numa direção que se situa (e hoje pode situar-se) para além destas preocupações e de suas autolimitações. Ou seja, se situa para além dos esforços de resolução de uma crise de legitimidade e fiscal do Estado. E, portanto, para além dos esforços de autoreprodução deste Estado e das condições econômico-sociais e políticas que ele ajuda a sustentar ${ }^{10(203)}$. 
É possível perceber que, ao considerar uma análise para além da 'resolução' de uma crise de legitimidade (aí se referindo ao Golpe Militar impetrado em 64 que promulgou um governo ilegítimo do ponto de vista dos procedimentos democráticos burgueses) e da crise fiscal (referindo-se ao período em que a economia brasileira sofre uma inflação de $80 \%$ ao ano, o crescimento do produto nacional bruto é baixíssimo, 1,6\% ao ano, e as taxas de investimento no País são quase zero), o autor tem em mente a crítica ao Estado como operador das mudanças defendidas pelos autores que apoiavam a tese da institucionalidade.

Fiel à compreensão marxista do fenômeno, Oliveira vai resgatar a noção de 'democracia progressiva' advinda da elaboração gramsciano-togliattiana de 'passagem para o socialismo' na qual conjuga a contradição 'conquista do Estado' e a 'dissolução/quebra do Estado'. Nesse sentido, o autor demonstra sua compreensão crítica sobre o papel do Estado no asseguramento das condições capitalistas de produção da saúde e a preocupação na tentativa de operar um plano de ação para Reforma Sanitária que avance em direção ao socialismo ${ }^{3}$. Quaisquer outras formas de atuação cairiam na contradição inerente da social-democracia (ou seja, realizar pequenas 'reformas', por meio da conciliação/negociação entre os interesses de frações de classes bastante distintas). Para reforçar a ideia de não ilusão com o Estado capitalista, Oliveira ${ }^{10}$ argumenta que:

[...] o que queremos frisar é que a noção de guerra de posição / democracia progressiva inclui a noção marxiana-lenilista de 'quebra do Estado'. Com a diferença (vis a vis uma situação de guerra de movimento) de que esta 'quebra' é pensada, aqui, como algo que se realiza (tem que se realizar) anteriormente a tomada do poder político do poder de estado. E como condição para tal. O que, obviamente, nos obriga a trabalhar com uma concepção do Estado capitalista que não se reduza à noção vulgar de um 'comitê de negócios', de uma fortaleza a ser assaltada desde fora, mas sim com uma visão do Estado capitalista que se situe mais na direção de algo como, por exemplo, a fórmula poulantziana onde $\mathrm{o}$ Estado aparece como a 'condensação material de uma relação de forças' e, portanto, como um campo possível de luta política revolucionária10(204).

As categorias 'guerra de movimento' e 'guerra de posição' permitem conduzir a perspectiva de uma 'democracia progressiva' em virtude da organização de uma luta política pelo avanço da tomada de poder no Estado e sua 'quebra' na sequência. Assim, depreende-se da leitura do autor que a 'guerra de posição', ou seja, o contínuo movimento do aparelhamento do Estado com militantes da reforma sanitária (no caso do momento sócio histórico em questão) representariam resistências concretas à forma jurídica e política do Estado no processo de condensação de forças que o leva em direção à sustentação da ordem capitalista. Em contrapartida a 'guerra de movimento' por fora do aparelho do Estado, por meio da militância sanitária, deveria articular-se com outras frentes setoriais a ponto de garantir a unidade de luta política suficiente para permitir a derrocada do Estado e reformular as bases de um novo modo de produzir. Como o autor aponta:

Ou seja, nos encontramos agora no núcleo da distinção entre guerra de posição e guerra de movimento. Uma vez que, como se sabe, a primeira corresponde a uma proposição estratégica orientada para os contextos nos quais o Estado capitalista já adquiriu claramente sua forma 'ampliada'. Ou seja, estendeu-se aos aparelhos privados e se tornou hegemônico, dirigente, mais do que meramente dominante e coercitivo ${ }^{\mathbf{1 0}(205)}$.

Nesse momento, o autor assume que a posição dos sanitaristas à época era na intersecção entre 'guerra de posição' e 'guerra de movimento'. Em sua perspectiva, o alcance de uma 'democracia progressiva' só poderia ser realizada mediante o enfrentamento das 
forças que operam o Estado (na sua perspectiva 'ampliada') em destituir os elementos concretos (formas privadas de prestação da saúde, representações sociais sobre a saúde pública e mercantilização do trabalho em saúde) para congregar as forças sociais suficientes em direção 'a quebra' do aparelho do Estado. Oliveira esclarece sua ideia:

[...] a ideia de guerra de posição, e sua sucedânea (democracia progressiva) apontam, conjuntamente, no sentido da necessidade de promover, naqueles contextos, uma ação política, e ideológica (moral, cultural) ampla, que inclui, além dos problemas (por si só complexos) ligados à 'quebra' do aparelho de estado, todo o processo de luta pela hegemonia nos aparelhos, públicos e privados, de hegemonia e coerção 10(205).

Dessa forma, Oliveira ${ }^{10}$ tece, em nossa opinião, a mais pesada crítica ao movimento sanitário e à Saúde Coletiva na atualidade: a desconstrução da política pública como realizadora das funções sociais da saúde (ou, como em outros autores ${ }^{26}$, como promotora do 'bem comum'). Em que pese a realização dessa crítica contumaz, o autor percebia que as condições objetivas do processo histórico naquele período encaminhavam a ação política para outro sentido. Nesse âmbito, Oliveira ${ }^{10}$ interpela:

[...] como devem ser pensadas, alternativamente, as chamadas 'Políticas públicas' (e, mais particularmente, as 'Políticas Sociais') ao interior de um projeto de guerra de posição/democracia progressiva? [...] se as 'políticas públicas' jogam um papel razoavelmente claro como instrumento de manutenção e reprodução da ordem política e econômica dadas, como devem ser encaradas, alternativamente, num projeto de transformação radical, revolucionária (embora 'progressiva') este quadro? [...] como se colocam, mais concretamente, no âmbito das 'Políticas Públicas', as questões da 'quebra do Estado', e da luta pela hegemonia?10(206).
Assim, em uma tentativa de conciliar a teoria da Reforma na qual elaborava com o movimento do real, Oliveira ${ }^{10}$ realiza sua crítica ao movimento histórico: admitiu que a tese da institucionalidade findaria por guiar o processo de Reforma Sanitária e conduziu o debate a fim de conjugar as duas propostas em uma espécie de (sín)tese. $\mathrm{O}$ autor argumenta que:

a ideia de que a mera incorporação de novos (e mesmo heterodoxos) atores ao policy-making governamental, sem que esta incorporação se faça acompanhar de uma problematização e um enfrentamento dos temas básicos da 'quebra' do Estado e da luta pela hegemonia, apenas nos levará, na melhor das hipóteses, a repor, de uma forma modernizada e atualizada, a estratégia socialdemocrata de mera 'ocupação' e gestão 'humanizada' do Estado capitalista, com as conhecidas consequências políticas deste fato10(208).

Vive-se, atualmente, as consequências políticas desse fato. Conforme previsto por Oliveira ${ }^{4}$, amarga-se, no contexto atual, o desmonte a passos largos do SUS, especialmente no que tange à sua forma eminentemente 'pública'3,26. Mais que uma síntese, Oliveira ${ }^{\mathbf{1 0}}$ foi certeiro em combinar fidelidade teórica e leitura apropriada do movimento da história. Não é de se esperar que essa combinação tenha repercussões tão assustadoras para os estudantes dos cursos de saúde, especialmente ao se depararem com os acontecimentos atuais.

Diante da análise social de precisão 'cirúrgica' que foi feita por Oliveira ${ }^{10}$, que quase antevê os (des)caminhos do SUS e suas políticas públicas ao longo desses 30 anos, é possível fazer a seguinte reflexão: de forma muito sintética, a aposta do movimento foi, em grande medida, na tecnicalidade da gestão do SUS. Mesmo reconhecendo que não há separação absoluta entre ‘o político' e 'o técnico' em quaisquer processos gerenciais, a dimensão técnica, isto é, a 'crença' em operar as políticas de saúde nos espaços institucionais conquistados no interior do Estado brasileiro, tornou-se prioridade. 


\section{Paim: revisitando a Reforma Sanitá- ria Brasileira 20 anos depois}

É largamente reconhecida no campo da saúde coletiva a contribuição à reflexão sobre a natureza e a trajetória do movimento da RSB por parte do médico Jairnilson Paim. Atualmente, Paim, doutor em saúde pública e mestre em medicina, é professor titular em política de saúde do Instituto de Saúde Coletiva da Universidade Federal da Bahia. Nos debates sobre reflexões críticas acerca do processo de implantação do SUS, não pode se furtar das contribuições que Paim vem propiciando ao conjunto do campo.

Na realidade, esse autor, em seu livro que teve como fonte sua tese de doutorado, 'Reforma Sanitária Brasileira: contribuição para a compreensão e crítica, 2008', realiza um trabalho notável ao recuperar a história crítica do processo da Reforma Sanitária no Brasil. Nele, Jairnilson vai além da formulação do SUS, envolvendo o projeto constituinte, com revisão crítica desde a criação do Centro Brasileiro de Estudos de Saúde (Cebes) nos anos 1970 e seu impacto para a mobilização da consciência sanitária até a sua agregação ao movimento político pela redemocratização do País nos anos 1980. Há também uma revisão crítica dos governos republicanos, destacando as idas e vindas da legislação e normatização do SUS nas várias conjunturas dos períodos presidenciais.

Sua obra apresenta uma conclusão relacionada com a revisão do conceito de Reforma Sanitária e com acirrados comentários sobre os desafios da Reforma para o futuro. De forma bem crítica, Paim conclui

que a Reforma Sanitária representa uma reforma social inconclusa, passando por diversos momentos de um ciclo: era uma ideia que ia se plasmando na medida em que se procedia a uma crítica ao sistema de saúde durante a ditadura'(291).

Paim esclarece que a Reforma Sanitária foi originária de um movimento ancorado no âmbito da sociedade civil, o que se deve valorizar como um grande atributo para a assunção da saúde enquanto um direito social. Contudo, ao longo dos anos 1990, assiste-se ao afastamento dessa construção, associando-se de forma muito intensa à luta institucional, especificamente em um processo de valorização do espaço no interior do Estado brasileiro. Paim esclarece:

Enquanto as iniciativas anteriores de reforma da saúde estavam ligadas ao Estado (com foco nos portos e centros urbanos), quando não desencadeadas fundamentalmente pela ação estatal, a Reforma Sanitária ou Reforma Democrática da Saúde, objeto desta investigação nasceu da sociedade civil e só, posteriormente, partiu para a conquista do Estado1(293).

É importante reconhecer os limites que as políticas públicas dispõem, especialmente no contexto do capitalismo contemporâneo, em que o Estado se vê cada vez mais associado aos interesses das reformas neoliberais sob o ditame do capital de dominância financei$\mathrm{ra}^{\mathbf{2 7}}$. Tem sido frequente no Estado brasileiro a adoção de políticas econômicas restritivas, processos de liberalização e abertura de mercados, com o avanço de privatizações, em geral e na saúde em particular, especialmente ao longo dos anos 1990, 2000 e $2010^{27}$.

Parte-se da ideia que o Estado não pode ser tomado como algo externo ao capital, especialmente aos efeitos atuais da dinâmica do capitalismo contemporâneo e sua crise com ataques frontais aos direitos sociais. Considera-se que a relação Estado/Capital deve ser compreendida por seu aspecto orgânico. Isto significa entender que não existe separação entre o Estado e o capital e que as relações entre eles não são somente relações de exterioridade. A forma Estado deriva das contradições da dinâmica do capital, na qual ela atribui ao Estado sua natureza capitalista, assegurando a troca das mercadorias, na sua forma-valor, e a própria exploração da força 
de trabalho27,28. O Estado não constitui mero resultado da vontade da classe dominante, mas, sim, de um determinado modo de produção e das relações sociais que lhe são inerentes. Por isso pode-se entender os sentidos das contrarreformas que o Estado capitalista vem adotando no contexto do capitalismo financeirizado e seus efeitos na saúde, em particular.

Assim, deve-se reconhecer a importante reflexão crítica de Paim quando menciona o direcionamento estreito que o movimento da Reforma Sanitária tomou, distanciando-se de um projeto societário para aquele que privilegia o espaço de atuação no ambiente estatal. Paim adverte que:

[...] diversos estudos, investigações, ensaios, position papers, debates e reflexões empreendidos sobre a RSB nas últimas décadas fixaram-se na sua dimensão institucional, ou seja, no SUS, negligenciando outros elementos fundamentais do projeto origina|1(293).

Assiste-se com perfeita clareza na atualidade um movimento de duas vias que revela a problemática que indicamos. De um lado, presencia-se um SUS cada vez mais distante de seu caráter emancipatório - 'civilizatório' e ‘socialista' - que o formou; de outro, destaca-se uma retórica da Reforma Sanitária bastante afastada nos propósitos políticos que tem conseguido formular, reforçada por debates técnico-administrativos. Paim é enfático nesse propósito:

Ainda assim, no final da década de oitenta, admitia-se que o processo da Reforma Sanitária supunha o desenvolvimento do capitalismo brasileiro e o percurso da sua superação para o socialismo, bem como a conquista da cidadania plena e a democratização da vida social. O trem da história, porém, parece ter seguido por outros trilhos'1(293-294).

É interessante notar como essa breve passagem evidencia os rumos frágeis que o Movimento da Reforma Sanitária seguiu, encerrando-se no caminho institucional e setorial. Paim não poupa comentários críticos a esse processo e chama atenção de todos do campo da saúde coletiva para uma necessária reflexão crítica. Diz ele:

[...] o confinamento da RSB à dimensão setorial e a submissão do SUS às 'manobras da política' (BERLINGUER, 1988a), tornando-o refém do clientelismo e do partidarismo, representam sérias limitações a exigir uma avaliação crítica1(296).

O desenvolvimento do SUS ao longo de sua existência de 30 anos foi marcado por tensões no âmbito das políticas governamentais, não restritas ao setor saúde. Vários aspectos vêm enfraquecendo a capacidade de arrecadação do Estado brasileiro e prejudicando, por exemplo, o financiamento do SUS, passando de um subfinanciamento histórico para um processo de desfinanciamento, a partir da Emenda Constitucional $\mathrm{n}^{\circ} 95$ que congela o gasto público, em geral, e da saúde, em particular, por 20 anos, sem limitar o crescimento das despesas com juros e outras de caráter financeiro $^{27}$. Merecem destaque, ainda: $o$ aumento das transferências dos recursos públicos às Organizações Sociais de Saúde (OSS) - de gestão privada -, por meio da implementação da Lei de Responsabilidade Fiscal (em vigor há 18 anos) que limita o aumento do gasto com pessoal, favorecendo o incremento das despesas com serviços de terceiros; o crescimento das renúncias fiscais decorrentes da dedução dos gastos com planos de saúde e símiles no imposto de renda pessoa física e jurídica e das concessões fiscais às entidades privadas sem fins lucrativos (hospitais) e à indústria químico-farmacêuticas; a permissão à entrada do capital estrangeiro na saúde por meio da aprovação da Lei no 13.097/2015; a instituição da Emenda Constitucional (EC) no 86/2015 que reduz o financiamento do SUS ${ }^{27}$.

Sabe-se que o enfrentamento a essas medidas não pode passar por uma luta apenas concentrada no âmbito do setor saúde. É preciso reconhecer que o seu enfrentamento 
exige uma atuação mais ampla de vários setores e de distintos segmentos do movimento social não restritos à saúde. Paim corrobora essa visão e insiste no seguinte alerta:

[...] os resultados apresentados no presente estudo indicam que as condições concretas em que a RSB foi implantada reduziram a sua práxis a uma reforma parcial setorial, ilustrando algumas das consequências da revolução passiva1(300).

Paim não economiza nas suas palavras críticas e estas devem servir de reflexão dos jovens sanitaristas: "Mesmo não sendo pouco, o que se desenvolveu no país foi uma reforma parcial de natureza setorial e institucional traduzida pela implementação do SUS"1(302). Ainda, esse autor acrescenta de forma enfática:

em linhas gerais, esta é a tese defendida: a Reforma Sanitária Brasileira reduziu-se a uma reforma parcial, inscrita nas suas dimensões setorial e institucional com a implantação do Sistema Único de Saúde (SUS). O resto é retórica1(309).

Não resta dúvida que a contribuição crítica de Paim acerca do sentido do caminho do movimento da Reforma Sanitária impulsiona uma reflexão mais aprofundada dos limites de implantação da saúde pública universal pela perspectiva do Estado e de uma restrição de defesa da saúde ao campo setorial. Parece que o movimento deve ser outro, isto é, apostar na inversão da lógica de trajetória desenvolvida e fortalecer uma construção por uma via de tática radical, visando à defesa de uma saúde popular. Nessa perspectiva, a partir do pensamento crítico de Paim, indicamos como reflexão geral as palavras de Hirsch ${ }^{29}$ :

Só se podem esperar mudanças no terreno da política governamental, caso haja uma permanente pressão popular. Ela é também uma pré-condição para que as estruturas democráticas, reduzidas a uma mera formalidade, possam ganhar novamente conteúdo; e para que a democracia tenha algo a ver com a autodeterminação, não se esgotando apenas 'a intermediação de lógicas da valorização capitalista'29(306).

\section{Considerações finais}

A construção de outra narrativa para o ensino da RSB parece fundamental para entender a escolha política adotada por esse movimento: ocupação de posições estratégicas no cenário institucional. Esse caminho fica perceptível quando se analisam os argumentos de Arouca, Oliveira e Paim nos textos aqui trabalhados. Ainda que esses textos tenham sido de períodos sócio-históricos distintos, permitem a compreensão da insistência do processo da Reforma Sanitária em privilegiar sua atuação no âmbito do aparato estatal.

Mesmo reconhecendo que a sociedade brasileira e o capitalismo tenham passado por mudanças em relação aos anos vivenciados pelos autores-atores aqui tratados, entende-se ser fundamental realizarmos uma ponderação. Em termos marxianos, a história é um 'livro aberto', e por mais que a conjuntura tenha um peso considerável nas apostas políticas, tratava-se de considerar a força do capital e sua relação orgânica com o Estado, e não se iludir com este.

Compreende-se que o estudo do passado só é relevante quando está a serviço do presente; e, nessa direção, pensar historicamente significa pensar politicamente ${ }^{30}$. A saúde coletiva e as forças sociais que defendem a saúde como um direito, pensadas na perspectiva da história crítica e, portanto, na direção de uma 'memória socialmente útil' como diz Breilh'2, pressupõem revisitar a construção do campo em suas contradições.

Tendo essa perspectiva em mente, é possível dizer que os fragmentos dos três autores clássicos analisados convergem ao ensinar 
outra narrativa sobre a escolha política feita: a tese socialista foi abandonada gradualmente em função das condições objetivas impostas, e o Estado se tornou a aposta do movimento, restringindo-se à operação das políticas públicas no campo setorial.

O investimento nessa outra narrativa, ao ensinar a história da Reforma Sanitária, pode contribuir para a ampliação de um pensamento crítico ao futuro da saúde pública no País, especialmente em contexto de restrições democráticas.

\section{Colaboradores}

Carnut L (0000-0001-6415-6977)*, Mendes A (0000-0002-5632-4333)* e Marques MCC (0000-0002-7461-3710)* colaboraram igualmente na construção deste manuscrito.

\section{Referências}

1. Paim JS. Reforma sanitária brasileira: contribuição para a compreensão e crítica. Salvador: EDUFBA; Rio de Janeiro: Fiocruz; 2008.

2. Teixeira SF, organizadora. Reforma sanitária: em busca de uma teoria. São Paulo: Cortez; 1989.

3. Dantas AV. Do socialismo à democracia: tática e estratégia na Reforma Sanitária Brasileira. Rio de Janeiro: Fiocruz; 2017.

4. Fleury S. Revisitar a teoria e a utopia da Reforma Sanitária. In: Fleury S, organizadora. Teoria da Reforma Sanitária: diálogos críticos. Rio de Janeiro: Fiocruz, 2018.

5. Cammarota A, Faccia K. Enseñar Historia en las carreras de salud. Interface (Botucatu) [internet]. 2018 [acesso em 2019 jun 20]; 22(67):1003-1015. Disponível em: http://dx.doi.org/10.1590/1807-57622017.0458.
6. Brandão G. Linhagens do pensamento político brasileiro. Dados-Rev Cienc Soc. 2005; 48(2):231-269.

7. Dallari SG. O direito à saúde. Rev. Saúde públ. 1988; 22:57-63.

8. Santos JS, Teixeira CF. Política de saúde no Brasil: produção científica 1988-2014. 2016; 40(108):219-230.

9. Sobral LF, Barros ÉL, Carnut L. A área de política, planejamento e gestão em saúde nas graduações em saúde coletiva no Brasil. Trab. educ. saúde. 2017; 15(3):879-894.

10. Oliveira JA. Reformas e Reformismo: "Democracia Progressiva" e Políticas sociais (ou "Para uma teoria política da Reforma Sanitária”). Cad. Saúde Publica. 1987; 4(3):360-387.

11. Arouca S. O dilema preventivista: Contribuição para 
a compreensão e crítica da medicina preventiva. Rio de Janeiro: Fiocruz/Unesp; 2003.

12. Breilh J. Espejo, adelantado de la ciencia crítica: uma "antihistoria" de sus ideas en salud. Ecuador: Corporacion Editora Nacional; 2016.

13. Paiva CHA, Teixeira LA. Reforma sanitária e a criação do Sistema Único de Saúde: notas sobre contextos e autores. História, Ciências, Saúde - Manguinhos. 2014; 21(1):15-35.

14. Almeida Neto AS. Utopia, representação e memória. In: Almeida Neto AS. Representações utópicas no ensino de História. São Paulo: Unifesp. 2011. p. 23-66.

15. Bauer MW. Análise de conteúdo clássica: uma revisão. Bauer MW, Gaskell G. Pesquisa qualitativa com texto, imagem e som: um manual prático. 8. ed. Petrópolis: Vozes; 2000. p. 189-217.

16. Marx K. A mercadoria. In: Marx K. O capital: crítica da economia política. Livro I: O processo de produção do capital. São Paulo: Boitempo; 2013. p. 113-158.

17. Smith A. A riqueza das nações: investigação sobre sua natureza e suas causas. São Paulo: Abril Cultural; 1983.

18. Kon A. Economia de serviços. Rio de Janeiro: Elsevier; 2004.

19. Meirelles DS. O conceito de serviço. Rev Econ Polit. 2006; 26(1):119-136.

20. Paim JS, Almeida-Filho N. Saúde coletiva: uma "nova saúde pública" ou campo aberto a novos paradigmas? Rev Saude Publ. 1998; 32(4):299-316.

21. Campos GWS. Saúde pública e saúde coletiva: campo e núcleo de saberes e práticas. Ciênc. Saúde Colet. 2000; 5(2):219-230.
22. Escorel S. Reviravolta na saúde: origem e articulação do movimento sanitário. Rio de Janeiro: Fiocruz; 1999.

23. Leavell HR, Clarck EG. Medicina Preventiva. São Paulo: McGraw-Hill do Brasil; Rio de Janeiro: Fename; 1978.

24. Marx K. Crítica ao Programa de Gotha. São Paulo: Boitempo; 2012.

25. Nogueira RP, Gomes RM. Capitalismo e saúde. Rio de Janeiro: Cebes; 2012.

26. Correia MOG. Por uma crítica imanente sobre os limites das políticas públicas de direitos sociais e o Estado na produção do bem comum no modo de produção capitalista. Saude Soc. 2015; 24(S1):55-65.

27. Mendes A, Carnut L. Capitalismo contemporâneo em crise e sua forma política: o subfinanciamento e o gerencialismo na saúde pública brasileira. Saúde Soc. 2018; 27(4):1105-1119.

28. Caldas CO. A teoria da derivação do Estado e do direito. São Paulo: Outras Expressões; 2015.

29. Hirsch J. Teoria Materialista do Estado: processos de transformação do sistema capitalista de Estado. Rio de Janeiro: Revan; 2010.

30. Chesneaux J. Devemos fazer tábula rasa do passado? Sobre a história e historiadores. São Paulo: Ática S. A.; 1995.

Recebido em 03/06/2019 Aprovado em 11/09/2019 Conflito de interesses: inexistente Suporte financeiro: não houve 